\title{
Mucinous borderline ovarian tumors: Analysis of 75 patients from a single center
}

\author{
Duygu Kavak Cömert ${ }^{1}$, Işın Üreyen², Alper Karalok ${ }^{2}$, Tolga Taşçı², Osman Türkmen², Reyhan Öcalan², Taner Turan², \\ Gökhan Tulunay ${ }^{2}$ \\ ${ }^{1}$ Department of Obstetrics and Gynecology, Ankara Training and Research Hospital, Ankara, Turkey \\ ${ }^{2}$ Department of Obstetrics and Gynecology, Etlik Zübeyde Hanım Women's Health Training and Research Hospital, \\ Ankara, Turkey
}

\section{Abstract}

Objective: To analyze the clinicopathologic features, recurrence and survival rates, reproductive history, and treatment of patients with mucinous borderline ovarian tumors (mBOTs).

Material and Methods: Patients with a diagnosis of mBOT were evaluated retrospectively. Patients with borderline ovarian tumors other than mucinous type and concomitant invasive cancer were excluded.

Results: A total of 75 patients were identified. Median age was 38 years. The most common symptom was pain (42.7\%). Median CA-125 level was $23.5 \mathrm{IU} / \mathrm{mL}$ (range, 1-809 IU/mL). Median tumor size was $200 \mathrm{~mm}$ (range, 40-400 mm), and 6.7\% of mBOTs were bilateral. Thirty-six (48\%) patients underwent staging surgery. Two patients (5.9\%) had nodal involvement. One patient received platinum-based adjuvant chemotherapy. One (1.3\%) patient had recurrence. None of the patients died because of the ovarian tumor. A total of 43 patients had conservative surgery.

Conclusion: Prognosis of mBOTs is excellent, and fertility-sparing surgery should be considered in the reproductive age group. Furthermore, the necessity of staging surgery is controversial. (J Turk Ger Gynecol Assoc 2016; 17: 96-100)

Keywords: Borderline ovarian tumor, mucinous, surgical approaches

Received: 2 March, 2016 Accepted: 13 April, 2016

\section{Introduction}

Borderline ovarian tumors (BOTs) comprise $10-20 \%$ of ovarian malignancies (1). Although they are similar to malignant epithelial ovarian tumors in some of the histologic characteristics, these types of tumors do not have destructive stromal invasion (2). Their prognosis is much better than that of carcinoma (3). BOTs can be divided into serous, mucinous, endometrioid, clear cell, and Brenner types (4). Median age at diagnosis is 10-20 years younger than that of invasive ovarian cancer, and BOTs are usually diagnosed at an early stage $(4,5)$.

Up to $30-50 \%$ of BOTs are mucinous (4). Mucinous BOTs (mBOTs) were classified into "intestinal" or "Mullerian" (endocervical) types. However, according to a new classification, endocervical mBOT is a part of seromucinous tumors and intestinal mBOT is accepted as mBOT (6). mBOTs are rarely associated with pseudomyxoma peritonei. However, $75 \%$ of tumors associated with pseudomyxoma peritonei have an appendiceal origin (7). In the past, guidelines often recommended removal of the appendix in patients with mBOT. However, appendectomy is controversial today, and some authors suggest appendectomy only if the appendix appears macroscopically abnormal (4). More than $90 \%$ of patients with mBOT have stage I disease, and fewer than $10 \%$ are bilateral (7).

The purpose of this study was to analyze the clinicopathologic features, recurrence and survival rates, reproductive history, and treatment of patients with mBOT.

\section{Material and Methods}

The patients who were diagnosed in our institution between January 1990 and April 2014 with a final diagnosis of mBOT were evaluated retrospectively. Patients with BOT other than mucinous type and patients with concomitant invasive cancer were not included. Information about the patients' pathologic reports, medical records, and operation notes were extracted from the computerized database of the gynecologic oncology department. The clinical, surgical, and pathologic details (age, menopausal status, history of infertility, complaint at admission, tumor size, bilaterality, type of operation, nodal involvement, CA-125 levels, histologic subtype, and follow-up) of patients were obtained from the archives. Ethics committee approval was received from the local ethics committee of the hospital where this research was conducted. Written informed consent was not received from patients due to the nature of the study. 
The treatment of patients with these tumors was altered during the period of research. The staging surgery was decided according to the time of the diagnosis of the tumor (intraoperatively vs postoperatively) and the opinion of the surgeon. For the premenopausal women who desire pregnancy, fertilitysparing surgery (conservative surgery) was preferred. Radical surgery (total abdominal hysterectomy and bilateral salpingooophorectomy) was done for women who are not willing to be pregnant again. Preservation of the uterus and minimum one ovary was performed for the fertility-sparing surgery. This description contains unilateral adnexectomy (UA), unilateral cystectomy (UC), UA with contralateral cystectomy (UA+CC), and bilateral cystectomy (BC), with or without staging surgery. All of the patients had laparotomy for surgery.

Samples gained from surgery were assessed by pathologists who are skilled in gynecologic pathology. Seventy-five patients with mBOT were included in the study; 14 of these 75 patients were sent to our institution from other hospitals because of having mBOT. After the pathologic specimens were confirmed as BOT by our pathologists, we finalized the diagnosis of patients as BOT. For identification of BOT, World Health Organization (WHO) diagnostic norms were utilized. The criterion for being BOT is showing uncharacteristic epithelial proliferation lacking stromal invasion. Staging surgery was performed by using 1988 International Federation of Gynecology and Obstetrics (FIGO) staging system for ovarian carcinoma.

Patients were taken to abdominal ultrasonography, performed pelvic examination, CA-125 levels, blood biochemistry, and complete blood count every 3 months for 2 years, every 6 months till the fifth year, and once a year subsequently. If required, thoracic, abdominal, or pelvic computed tomography was performed. The time between the surgical treatment and the patients' last visit was assessed as follow-up time. Time to recurrence was defined as the period between surgery and relapse.

\section{Statistics}

Data assessment was made by using the SPSS 11.5 for windows (SPSS Inc.; IL, USA). P values $<0.05$ were accepted as statistically significant.

\section{Results}

\section{Clinicopathologic factors}

A total of 250 patients having a final diagnosis of BOT between January 1990 and April 2014 in our institution were identified, of whom 175 with cell types other than mucinous were excluded. The remaining 75 patients had mBOT. Median age at diagnosis was 38 years (range, 16-77 years). Sixty percent of the patients were premenopausal, and $4 \%$ had a history of infertility. The most common symptom before diagnosis was pain (42.7\%), and $25.3 \%$ of patients had sensation of bloating. The characteristics of the patients are shown in Table 1.

Preoperative CA-125 levels of 46 patients were known. Median CA-125 level was $23.5 \mathrm{IU} / \mathrm{mL}$ (range, 1-809 IU/mL). Eighteen patients had a CA-125 level above $35 \mathrm{IU} / \mathrm{mL}$. Median tumor size was $200 \mathrm{~mm}$ (range, $40-400 \mathrm{~mm}$ ). Only $6.7 \%$ of mBOTs were bilateral.
Table 1. The clinical characteristics of the patients, $n=75$

\begin{tabular}{|l|c|}
\hline Characteristics & Median (range), n (\%) \\
\hline Age & $38(16-77)$ \\
\hline Menopausal status & $14(18.7)$ \\
\hline Not known & $45(60)$ \\
\hline Premenopausal & $16(21.3)$ \\
\hline Postmenopausal & \\
\hline History of infertility & $33(44)$ \\
\hline Not known & $3(4)$ \\
\hline Yes & $39(52)$ \\
\hline No & $14(18.7)$ \\
\hline Complaint at admission & $32(42.7)$ \\
\hline Absent & $19(25.3)$ \\
\hline Abdominal pain & $3(4)$ \\
\hline Sensation of bloating & $1(1.3)$ \\
\hline Abnormal vaginal bleeding & $6(8)$ \\
\hline Urinary incontinence & \\
\hline Not known & \\
\hline
\end{tabular}

Stage I disease was observed in $45 \%$ and stage III only in $3 \%$ of patients. Among 75 patients, 43 (57\%) had conservative surgery. Among these 43 patients, 34 had UA, 5 had UA+UC, 3 had UC, and 1 had BC. Staging surgery was not performed in 39 (52\%) patients. Thirty-six (48\%) patients underwent staging surgery. Eleven of these 36 patients had staging surgery at the second operation (re-staging). Among these 36 patients, 34 had lymphadenectomy. Median number of harvested lymph nodes was 52 (range, 21-105). These numbers were 36 (range, 21-67) and 19 (range, 0-38) for pelvic and para-aortic regions, respectively. Among the 34 patients, two (5.9\%) had nodal involvement. One patient had pelvic and one had para-aortic involvement. Omentectomy was performed in 53\% of patients, and omental metastasis was not detected in any of these patients. Appendectomy was performed in 44 (58.7\%) patients, and none of the patients had involvement of the appendix. No other pathologic finding was detected in the appendectomy speciments. Abdominal cytology was reported in 47 patients of which five $(6.7 \%)$ had positive cytology, reported as atypical cells. No patient was reported to have microinvasion or micropapillary growth pattern. Only one patient received platinumbased adjuvant chemotherapy (Carboplatin flacon, $450 \mathrm{mg} / 45$ $\mathrm{mL}$; Eczacıbaşı, Turkey). Reason of adjuvant therapy was nodal involvement in this patient. None of the patients had adjuvant radiotherapy. Median follow-up time was 51 months (range, 1-222 months). The clinical features and the type of the operations are shown in Table 2.

\section{Recurrence and survival}

Median follow-up time was 51 months (range, 1-222 months). Only one (1.3\%) patient had recurrence. None of the patients died because of the ovarian tumor. The patient with recurrent 
Table 2. The pathologic and surgical characteristics of patients, $\mathrm{n}=75$

\begin{tabular}{|l|c|}
\hline Characteristics & Median (range), $\mathbf{n}$ (\%) \\
\hline Mean tumor size (mm) & $200(40-400)$ \\
\hline Bilaterality & $5(6.7)$ \\
\hline Type of operation & $34(45.3)$ \\
\hline UA & $5(6.7)$ \\
\hline UA+CC & $3(4.0)$ \\
\hline UC & $1(1.3)$ \\
\hline BC & $30(40.0)$ \\
\hline TAH+BSO & $2(2.7)$ \\
\hline BA & $36(48.0)$ \\
\hline Staging surgery & $11(14.7)$ \\
\hline Restaging & $47(62.6)$ \\
\hline Abdominal cytology & $40(53.3)$ \\
\hline Omentectomy & $3(4.0)$ \\
\hline Peritoneal biopsy & $44(58.7)$ \\
\hline Appendectomy & $34(45.3)$ \\
\hline Lymphadenectomy & $2(5.9)$ \\
\hline Nodal involvement (n=34) & $\begin{array}{l}\text { UA: unilateral adnexectomy; UA+CC: unilateral annexectomy+contralateral } \\
\text { cystectomy; UC: } \text { unilateral cystectomy; BC: bilateral cystectomy; TAH+BSO: } \\
\text { total abdominal hysterectomy+bilateral salpingoophorectomy; BA: bilateral } \\
\text { adnexectomy }\end{array}$ \\
\hline
\end{tabular}

mBOT had recurrence twice: her first recurrence was after 61 months following the first surgery and the second recurrence was 91 months after first surgery. She had right unilateral salpingooferectomy (USO) in the first operation conducted in another institution. Preoperative CA-125 level was unknown. Resurgery for staging had not been performed. She had left ovarian cystectomy after both the first and second recurrences. Both pathology results revealed mBOT. She has been free of disease for 116 months after the second recurrence, and she had a term pregnancy after her second recurrence.

\section{Reproductive history}

A total of 43 patients had conservative surgery in the first operation. Median age of these patients was 29 years (range, 16-40 years). Among these patients, desire for pregnancy was reported in the files of 14 patients. In all, 12 patients got 14 pregnancies. Eleven pregnancies went to term, 1 pregnancy terminated with abortion, and the pregnancy outcomes of 2 patients were not known.

\section{Discussion}

BOTs constitute $10-20 \%$ of ovarian malignancies (1), and $30-50 \%$ of BOTs are mucinous (4). In the literature, there is limited data evaluating only mBOTs. We retrospectively analyzed patients with mBOT.
It is known that BOTs are usually seen in young women. We found that median age at diagnosis was 38 years and that $60 \%$ of patients were premenopausal. There are similar findings in the literature regarding median age at diagnosis. A retrospective study from Italy assessed 43 patients with BOT and reported the median age as 49 years (8). Ayhan et al. (9) evaluated recurrence and prognostic factors in 100 patients with BOT and found that the mean age at diagnosis was 41.7 years. Similarly, Uysal et al. (10) reported the mean age of patients with BOT as 37.7 years, and Desfeux et al. (11) identified that the mean age at diagnosis was 45 years. All these studies evaluated not only patients with mBOT but also the other patients with other types of BOT.

In our series, the most common symptoms were pain (42.7\%) and sensation of bloating (25.3\%). In the literature, there were studies evaluating patient complaints. Although these studies include patients with all types of BOT, they don't specifically focus on only the patients with mBOT . Like our study, in a French retrospective multicenter study, Fauvet et al. (12) evaluated 360 women treated for BOT and pointed out that the most common symptom at diagnosis was pelvic pain (27\%). Ayhan et al. (9) reported that the most common complaints at admission were abdominal mass (37\%) and abdominal pain (29\%). In the study by Messalli et al. (8), $49 \%$ of patients with BOT were asymptomatic and in premenopausal patients the most common symptom was menstrual disorders (44\%).

CA-125 level is elevated in patients with epithelial ovarian tumors and used in diagnosis and follow up (13). In our study the mean preoperative CA-125 level was $23.5 \mathrm{IU} / \mathrm{mL}$ (range, $1-809 \mathrm{IU} / \mathrm{mL}$ ) and 18 patients had a CA125 level above $35 \mathrm{IU} / \mathrm{mL}$. An article that aimed to understand the outcomes of women with mBOT identified that carcinoembryonic antigen (CEA) could be used in the diagnosis and follow-up (14). Engelen et al. (13) analyzed preoperative and postoperative serum levels of tumor markers. They reported that CA 19-9 level was elevated more than CA-125 and CEA levels in mBOT. Gotlieb et al. (15) pointed out that $70 \%$ of patients with serous BOT had elevated CA-125 levels, while $30 \%$ of patients with mBOT did. CA- 125 level does not seem to be a good marker in the diagnosis and follow-up of patients with mBOT.

mBOTs are characterized by their large size. Messalli et al. (8) analyzed patients with BOT retrospectively and found that serous BOTs $(20-230 \mathrm{~mm})$ were smaller than mBOTs $(40-354$ $\mathrm{mm})$. Brown and Frumovitz (14) examined mucinous tumors of the ovary-not only mucinous tumors of low malignant potential but also benign mucinous cystadenoma and invasive mucinous ovarian carcinoma-and reported that mucinous tumors are large cystic mass. The mean size was $18 \mathrm{~cm}$, and they were usually unilateral (14). In a population-based study from California that compared characteristics of different types of BOTs pointed out that the mean tumor size of serous BOTs was $9.8 \mathrm{~cm}$, while it is $16.4 \mathrm{~cm}$ in mBOTs. In that study, $28.7 \%$ of serous BOTs were bilateral, while $4.7 \%$ of mBOTs were (16). Our findings were similar with the literature. We found that median tumor size was $200 \mathrm{~mm}$ and that only $6.7 \%$ of mBOTs were bilateral.

Staging surgery is controversial in patients with BOT. Many authors reported that patients with mBOT that were limited to 
the ovary did not have lymph node metastases. A review from Italy, which was about early stage BOTs, included 15 studiesa total of 948 cases-and showed that 69 (6\%) patients had stage I disease, $10.3 \%$ had stage II, $19.2 \%$ had stage III, and $0.6 \%$ had stage IV (17). However, this study included patients with all types of BOT, not only mBOTs. These ratios were for both serous BOTs and mBOTs. Romagnolo et al. (18) compared the laparoscopic and laparotomic approach in patients with BOT. They found that in 35 patients with mBOT, 34 patients had stage I disease. Brown and Frumovitz (14) reported that in three series that included 146 patients with mBOT, none had lymphatic metastases. Kleppe et al. (4) investigated the incidence of mucinous neoplasm in the appendix in patients with mBOT and found that appendices of 13 patients with mBOT were removed and all of them were microscopically normal. Our findings were similar to the literature. Our results showed that staging surgery was performed in $48 \%$ of patients and that only $3 \%$ of patients had stage III disease. Among 34 patients who had lymphadenectomy, only 2 had nodal involvement. Omental metastases, peritoneal implants, involvement of the appendix, microinvasion, or micropapillary growth pattern were not seen in any of these patients.

One patient received platinum-based adjuvant chemotherapy (Carboplatin flacon, $450 \mathrm{mg} / 45 \mathrm{~mL}$; Eczacıbaşı, Turkey). The reason of adjuvant therapy was nodal involvement in this patient. None of the patients had adjuvant radiotherapy. Only one (1.3\%) patient had recurrence. None of the patients died due to the ovarian tumor. Our results showed that the prognosis of patients with mBOT was excellent. We did not compare the survival and recurrence rate between staged and unstaged patients, as no patients died because of mBOT and only one patient had recurrence. Winter et al. (19) compared the survival and recurrence rate between staged and unstaged patients with all types of BOT. They showed that there was no difference between staged and unstaged patients. In a retrospective study that aimed to show the prognostic importance of each step of the surgical staging in patients with serous BOT reported that by each skipping step of the surgical staging the recurrence risk of the patient increased (20). Trillsch et al. (21) analyzed the age-dependent differences in patients with all types of BOT and point out that younger patients had higher disease recurrence risk.

It is known that BOTs are usually seen in young women, and these patients may have desire for pregnancy. In the present study, median age of patients who had conservative surgery was 29 years. In many other studies, it was said that conservative surgery in patients with BOT could be acceptable (22-24). In our study, only one patient who had USO in the initial surgery (conservative group) had recurrence. She had recurrence twice. In both recurrences, she had cystectomy, and she has been free of disease since then. In our series, desire for pregnancy was reported in the files of 14 patients. We did not calculate the pregnancy rate, since we did not know whether the remaining 61 patients had desire for pregnancy.

Our study is a retrospective study. Furthermore, it does not compare survival and recurrence rates, and not calculate the pregnancy rates. One should consider these limitations in assessing our findings.
In conclusion, as prognosis of patients with mBOT is excellent, fertility-sparing surgery should be considered in the reproductive age group. Furthermore, the necessity of staging surgery is controversial, since mBOT is a clinically benign tumor.

Ethics Committee Approval: Ethics committee approval was received for this study from the ethics committee of Etlik Zübeyde Hanım Women's Heath Training and Research Hospital, Ankara, Turkey

\section{Informed Consent: N/A.}

Peer-review: Externally peer-reviewed.

Author Contributions: Concept - D.K.C., I.Ü., T.T.; Design - D.K.C, I. Ü., T.T.; Supervision - I.Ü., T.T.; Materials - I.Ü.; Data Collection and/or Processing - D.K.C., I.Ü.; Analysis and/or Interpretation - D.K.C., I.Ü., T.T., A.K., O.T.; Literature Review - D.K.C., R.Ö., G.T.; Writer - D.K.C., I.Ü.; Critical Review - A.K., T.T., O.T., R.Ö., G.T.; Other - A.K., T.T., O.T., R.Ö., G.T.

Conflict of Interest: No conflict of interest was declared by the authors.

Financial Disclosure: The authors declared that this study has received no financial support.

\section{References}

1. Suh-Burgmann E. Long-term outcomes following conservative surgery for borderline tumor of the ovary: A large population-based study. Gynecol Oncol 2006; 103: 841-7. [CrossRef]

2. Boran N, Cil AP, Tulunay G, Ozturkoglu E, Koc S, Bulbul D, et al. Fertility and results of conservative surgery for borderline ovarian tumors. Gynecol Oncol 2005; 97: 845-51. [CrossRef]

3. Prat J. Pathology of cancers of the female genital tract. Int $\mathrm{J}$ Gynecol Obstet 2012; 119S2: 137-50.

4. Kleppe M, Bruls J, Van Gorp T, Massuger L, Slangen BF, Van de Vijver KK, et al. Mucinous borderline tumors of the ovary and the appendix: A retrospective study and overview of the literature. Gynecol Oncol 2014; 133: 155-8. [CrossRef]

5. Gotlieb WH, Chetrit A, Menczer J, Yechezkel GH, Lubin F, Friedman $\mathrm{E}$, et al. Demographic and genetic characteristics of patients with borderline ovarian tumors as compared to early stage invasive ovarian cancer. Gynecol Oncol 2005; 97: 780-3. [CrossRef]

6. Heerlein M, Fotopoulou C, Harter P, Kurzeder C, Mustea A, Wimberger P, et al. Statement by the Kommission Ovar of the AGO: The new FIGO and WHO classifications of ovarian, fallopian tube and primary peritoneal cancer. Geburtsh Frauenheilk 2015; 75: 1021-7. [CrossRef]

7. Seidman JD, Ronnett BM, Kurman RJ. Pathology of borderline (low malignant potential) ovarian tumors. Best Pract Res Clin Obstet Gynaecol 2002; 16: 499. [CrossRef]

8. Messalli EM, Grauso F, Balbi G, Napolitano A, Seguino E, Torella M. Borderline ovarian tumors: features and controversial aspects. Eur J Obstet Gynecol Reprod Biol 2013; 167: 86-9. [CrossRef]

9. Ayhan A, Güven ESG, Güven S, Küçükali T. Recurrence and prognostic factors in borderline ovarian tumors. Gynecol Oncol 2005; 98: 439-45. [CrossRef]

10. Uysal A, Mun S, Uysal F, Öztekin M, Büyüktosun C, Şehirali S, et al. Borderline ovarian tumors: a study of 100 cases from tertiary care hospital. Contemp Oncol (Pozn) 2013; 3: 307-10. [CrossRef]

11. Desfeux P, Camatte S, Chatellier G, Blanc B, Querleu D, Lecuru F. Impact of surgical approach on the management of macroscopic early ovarian borderline tumors. Gynecol Oncol 2005; 98: 390-5. [CrossRef] 
12. Fauvet R, Poncelet C, Boccara J, Descamps P, Fondrinier E, Darai E. Fertility after conservative treatment for borderline ovarian tumors: a French multicenter study. Fertil Steril 2005; 82: 284-90. [CrossRef]

13. Engelen M, Bruijn H, Hollema H, Hoor KA, Willemse PHB, Aalders JG, et al. Serum CA 125, carcinoembryonic antigen, and CA 19-9 as tumor markers in borderline ovarian tumors. Gynecol Oncol 2000; 78: 16-20. [CrossRef]

14. Brown J, Frumovitz M. Mucinous tumors of the ovary: current thoughts on diagnosis and management. Curr Oncol Rep 2014; 16 : 389-97. [CrossRef]

15. Gotlieb WH, Soriano D, Achiron R, Zalel Y, Davidson B, Kopolovic J, et al. CA 125 measurement and ultrasonography in borderline tumors of the ovary. Am J Obstet Gynecol 2000; 183: 541-6. [CrossRef]

16. Morris CR, Liu L, Rodriguez AO, Cress RD, Snipes K. Epidemiologic features of borderline ovarian tumors in California: a populationbased study. Cancer Causes Control 2013; 24: 665-74.[CrossRef]

17. Tinelli R, Tinelli A, Tinelli FG, Cicinelli E, Malsavi A. Conservative surgery for borderline ovarian tumors: A review. Gynecol Oncol 2006; 100: 185-91. [CrossRef]

18. Romagnolo C, Gadducci A, Sartori E, Zola P, Maggino T. Management of borderline ovarian tumors: results of an Italian multicenter study. Gynecol Oncol 2006; 101: 255-60. [CrossRef]
19. Winter WE 3rd, Kucera PR, Rodgers W, McBroom JW, Olsen C, Maxwell GL. Surgical staging in patients with ovarian tumors of low malignant potential. Obstet Gynecol 2002; 100: 671-6. [CrossRef]

20. Trillsch F, Manher S, Vettorazzi E, Woelber L, Reuss A, Baumann $\mathrm{K}$, et al. Surgical staging and prognosis in serous borderline ovarian tumours (BOT): A subanalysis of the AGO ROBOT study. Br J Cancer 2015; 112: 660-6. [CrossRef]

21. Trillsch F, Manher S, Woelber L, Vettorazzi E, Reuss A, EwaldRiegler $\mathrm{N}$, et al. Age-dependent differences in borderline ovarian tumours (BOT) regarding clinical characteristics and outcomes: results from a sub-analysis of the Arbeitsgemeinschaft Gynaekologische Onkologie (AGO) ROBOT study. Ann Oncol 2014; 25: 1320-7. [CrossRef]

22. Rao GG, Skinner E, Gehrig PA, Duska LR, Coleman RL, Schorge JO. Surgical staging of ovarian low malignant potential tumors. Obstet Gynecol 2004; 104: 261-6. [CrossRef]

23. Ayhan A, Celik H, Taskiran C, Bozdag G, Aksu T. Oncologic and reproductive outcome after fertility-saving surgery in ovarian cancer. Eur J Gynaecol Oncol 2003; 24: 223-32.

24. Chan JK, Lin YG, Loizzi V, Ghobriel M, DiSaia PJ, Berman ML. Borderline ovarian tumors in reproductive-age women. Fertilitysparing surgery and outcome. J Reprod Med 2003; 48: 756-60. 